\title{
Axel Honneth: el conflicto social y los modos de la mirada. Apuntes para pensar el problema más allá del reconocimiento
}

\author{
Axel Honneth: the social conflict and the ways of the look. \\ Notes to think the problem beyond recognition
}

\author{
Jorge Ariel Palacio \\ Universidad Nacional de Cuyo \\ jpalacio38@gmail.com
}

\begin{abstract}
Resumen
En este trabajo abordaremos una de las formas que asume el conflicto social, considerando un comportamiento cotidiano: la mirada y los modos de representación que ella produce. El comienzo de nuestra argumentación está marcado por la teoría del reconocimiento de Axel Honneth. Sus contribuciones dan una perspectiva que nos permite unir el análisis de las luchas sociales con el problema de la mirada. Para ese trabajo estudiamos cómo Honneth construye un enfoque ético sobre la mirada, desde las ideas de reconocimiento e intersubjetividad. En ese sentido, comportamientos prácticos como la humillación social y la dominación social, materializados a través de la mirada, son leídos como el reverso negativo del reconocimiento. Buscamos pensar la mirada inserta en el conflicto social más allá del reconocimiento, ya que partimos de la hipótesis de que la noción de reconocimiento, como la piensa Honneth, asume presupuestos normativos que visualizan el conflicto como orientado a la consolidación de una comprensión mediatizada de la propia personalidad y a la autoafirmación del sujeto. Una vez mostrado tal punto nos adentramos a responder la pregunta: ¿cómo comprender el problema de la mirada en otra amplitud?
\end{abstract}

Palabras clave: visibilidad, invisibilidad, subjetividad, mirada objetivadora, mirada abyecta.

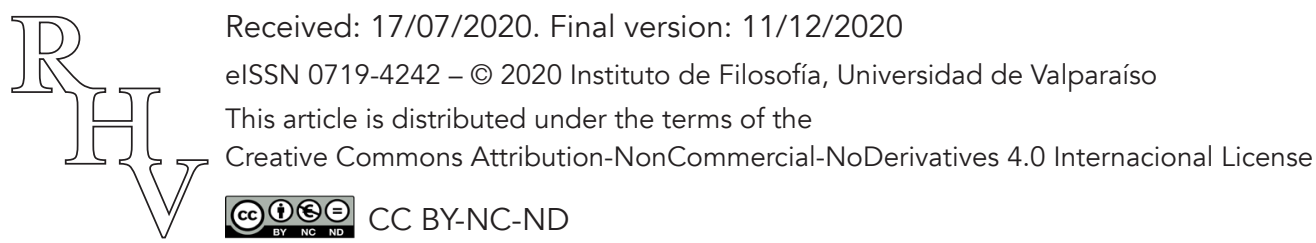


Axel Honneth: el conflicto social y los modos de la mirada. Apuntes para pensar el problema más allá del reconocimiento

Jorge Ariel Palacio

\begin{abstract}
In this paper we will address one of the forms that assume the social conflict, considering an everyday behavior: the look and the ways of representation that it produces. The beginning of our argumentation is marked by Axel Honneth's theory of recognition. His contributions give a perspective that allow us to unite the analysis of socials struggles with the problem of the look. For this work we study how Honneth build an ethical approach about the look, from the ideas of recognition and inter-subjectivity. In that sense, practical behavior like social humiliation and social domination, materialized through the look, are read as the negative reverse of recognition. We seek to think the look inserted in the social conflict beyond recognition, because we defend the hypothesis that the notion of recognition, as proposed by Honneth, assumes normative assumptions that visualize conflict as oriented to the consolidation of a mediated understanding of one's own personality and the self-affirmation of subject, as also assumes an evolutionary logic rationality. Once shown this, we will answer the question: how to understand/comprehend the problem of the look from a different perspective?
\end{abstract}

Keywords: visibility, invisibility, subjectivity, obyectifying look, abject look.

\title{
1. Introducción
}

Es sabido que, de manera temprana, la tradición filosófica occidental vinculó, aunque subrepticiamente, la praxis del reconocimiento con la ejecución de la mirada. Podríamos decir que la enunciación formal del reconocimiento como un saberse a sí mismo en el otro, encontró su articulación corporal-sensible en un mirarse en la mirada del otro, o en los ojos del otro, al menos como meta regulativa de un ideal de reciprocidad plena. Así es como ya en uno de sus primeros diálogos, Platón advierte el índice tentativo para la búsqueda del "sí mismo", del alma propia, en el reflejo de nosotros que habita en los ojos del otro y a través del cual nos vemos a nosotros mismos: "un ojo que quiere verse a sí mismo debe mirarse en otro ojo" (Platón 2017, 27), rezaba la expresión del filósofo. Pero también es cierto que, si abandonamos este acotado platonismo (de paso: que nada dice sobre Platón), no resultaría descabellado partir del supuesto de que el tipo de relaciones sociales entre las que nos constituimos a nosotros mismos no se caracterizan, sin más, por su continuidad homogénea entre quienes intervienen; al contrario: el único "a priori" admisible es justamente aquel que se reproduce desarticulando y excediendo los estrechos límites de nuestra voluntad individual, una facticidad cuya única orientación segura es el conflicto social, y en la que las miradas en las que se encuentran los ojos que se miran, el espacio para la identificación no asume solamente los modos del reconocimiento, sino los del no-reconocimiento, la discontinuidad, la ruptura y las formas, también, a través de las 
Axel Honneth: el conflicto social y los modos de la mirada. Apuntes para pensar el problema más allá del reconocimiento

Jorge Ariel Palacio

cuales la mirada del otro es resistida y rechazada, no pensada como potencial lugar en el que se concretiza una economía moral perfecta, sino también como el lugar en el que se produce la certeza negativa en torno a la inhabitabilidad de la vida.

Axel Honneth, quien al día de hoy es presentado como uno de los más importantes referentes de la Teoría Crítica de la Escuela de Frankfurt, se sumerge en el intento de pensar justamente estos problemas. Preocupado por las prácticas de menosprecios en virtud de las cuales la efectiva materialización de las instituciones del reconocimiento frustra sus excedentes normativos, estudia los modos públicos y cotidianos entre los que se constituyen diversas formas de humillación social. En ese recorrido atraviesa una interesante idea que se enlaza con lo desarrollado en el párrafo anterior, produciendo un nudo para el diálogo con otras tradiciones filosóficas que abordaron la cuestión del reconocimiento: lo que él denomina "invisibilidad". Primero, nos concentraremos en reconstruir -brevemente- dicho concepto. En esta misma dirección, destacaremos los supuestos epistémicos que estructuran su noción de "invisibilidad", mostrando que, en realidad Honneth, elabora dicha categoría proyectando una distinción tajante respecto de su contraparte: "visibilidad". Según nuestra manera de entenderlo, Honneth extrapola abiertamente el par reconocimiento-menosprecio para indicar que las modalidades de la mirada se configuran correspondiéndose a dichos fenómenos éticos. Si bien nuestra postura no es contraria a la del autor, creemos que es posible indagar más profundamente en torno a los desenlaces negativos de la mirada. Según nuestra posición, el marco de sus interpretaciones ofrece un enfoque donde las posibilidades de conflictos inmanentes expresadas en los comportamientos visuales - aun cuando exista conciencia de ellas- agotan su diversidad fenomenológica por estar proyectadas hacia un momento resolutivo donde el reconocimiento expresa el lugar desde el cual se enuncian críticamente sus aspectos negativos (I). En un segundo momento, dedicaremos nuestros esfuerzos por ampliar el registro de lo visual destacando política y fenomenológicamente el desempeño de dichas modalidades. Para ello estudiaremos la mirada objetivadora, que se corresponde con una práctica social que no es pura y exclusivamente gnoseológica -como parece sugerir el autor-; y la mirada abyecta, que -si bien está presente en las consideraciones del filósofo alemán- no está tematizada como tal (II).

\section{La cuestión visibilidad/invisibilidad en Honneth y el reconocimiento como marco interpretativo}

En un artículo que data del año 2001: "Invisibilidad. Estaciones de una Teoría de la Intersubjetividad", Honneth continúa desarrollando sus líneas de investigación planteadas en "La lucha por el reconocimiento", y se centra en una modalidad concreta por la

\footnotetext{
${ }^{1}$ De ahora en más "Invisibilidad".
} 
Axel Honneth: el conflicto social y los modos de la mirada. Apuntes para pensar el problema más allá del reconocimiento

Jorge Ariel Palacio

que las prácticas de menosprecio ${ }^{2}$ social adquieren cuerpo: la invisibilización, pensada esta última como contraparte negativa del reconocimiento. Como tal, ella es un proceso activo donde se pone de manifiesto un comportamiento en torno al cual una persona es completamente ignorada, como si no estuviese presente, o como si su presencia fuese deliberadamente soslayada. Contrariamente a esto, para Honneth, ser visible, o estar visibilizado, implica ser reconocido de forma singular y apreciativa.

En la filosofía de Honneth, el reconocimiento no refiere únicamente a un hecho cognitivo, no implica solamente la constatación en virtud de la cual se identifica lo previamente conocido y, por ende, algo o alguien es re-conocido; más aún, supone una praxis afirmativa en torno a la cual una persona es éticamente valorada: en cuanto a sus necesidades (amor), en cuanto a su integridad, o -dicho hegelianamente- como persona abstracta (derecho), y en cuanto a sus propias cualidades (solidaridad). En esta misma dirección podríamos pensar que la lesión o el agravio en cualquiera de estas dimensiones constitutivas del reconocimiento produce formas cotidianas de invisibilización social. Pero sin entrar todavía en ese tema, es preciso analizar la familiaridad que ostenta el doble significado que le cabe a la categoría de reconocimiento. En una de sus obras publicadas con posterioridad, "Reificación" - del 2005 y traducida al español en 2008- el filósofo alemán aporta elementos conceptuales que eventualmente permitirían vincular la ausencia de reconocimiento ético con la idea lukacsiana de cosificación. Según esta interpretación, la reificación

[s]e trata o bien de una unilateralización o de un endurecimiento de la postura de conocimiento ocurrida por la desvinculación de su propósito o, en el segundo caso, de una negación del reconocimiento a posteriori por un prejuicio o estereotipo. (Honneth 2007, 97)

La primera de las modalidades hace referencia a una persecución enérgica y ensimismada de una finalidad escindida de su contexto real. El deportista que, según Honneth, adoptando reglas del juego, persigue solamente sus objetivos, anula temporalmente los vínculos éticos que lo asocian con su contrincante, y tiende a visualizarlo como un obstáculo. En la segunda, por el contrario, la visualización del otro como una cosa u objeto refiere precisamente a la negación del reconocimiento: no hay praxis afirmativa alguna que valore éticamente la presencia del otro, sino que, en virtud de tramas ideológicas, referidas por Honneth como "estereotipos", "prejuicios", dicha persona es sustraída de aquella dimensión que lo hace sujeto desde la mirada del otro, y deviene cosa u objeto contemplado.

En esta breve secuencia delineada es posible analizar dos formas en torno a las cuales se configura la mirada, como así también dos formas en torno a las cuales se configura un

\footnotetext{
2 Esta categoría es extensamente desarrollada a lo largo de toda "La lucha por el reconocimiento", particularmente en los apartados 6, 7, y 8. Cfr. Honneth (1997, 160-205).
} 
cierto "ser visto". En una de ellas se replica el costado éticamente valorativo de la noción del reconocimiento. Quien mira le abre a quien es visto el lugar para que este pueda verse a sí mismo e intuya un trato recíproco en el que se constituye como socialmente "valioso" y donde el recorrido a través del cual se desenvuelve este circuito se supone permanentemente circular. Contrariamente, en las otras -tanto en la cosificación como en la invisibilidad- lo que sucede es que no hay espacio en el que la mirada de quien mira represente para quien es visto una instancia reflexiva mediante la cual éste pueda encontrar una imagen socialmente valiosa de sí mismo. Lo que se produce es una cierta discontinuidad que desmantela en quien mira el temple afectivo indicativo de la presencia de otro sujeto, y si bien quien mira está mirando, lo hace, o bien como si su mirada recayese sobre algo que no posee la capacidad de mirar y, por ende, devolverle la mirada -como si su mirada recayese sobre algo que no puede percatarse de su "ser visto", aun cuando, de hecho, esté siendo visto-; o bien como si aquel a quien percibe conviene no otorgarle la mirada.

Siguiendo la ruta trazada por el novelista Ralph Ellison en su obra "El hombre invisible", el filósofo alemán introduce en su artículo "Invisibilidad" la idea de "looking through", "mirar a través". Afirma:

Disponemos de la capacidad de demostrar nuestro desprecio a personas presentes mediante el hecho de comportarnos frente a ella como si no figurara físicamente en el mismo espacio. En este sentido, el ver a través de tiene enteramente un aspecto performativo, porque exige gestos o modos que dejen claro que los demás no sólo no son vistos accidentalmente, sino que no son vistos intencionalmente [...] (Honneth 2011, 166-167)

\section{Y agrega:}

Ver a través designa en general un hecho público: no solo el sujeto afectado, sino también las demás personas presentes en el espacio pueden normalmente comprobar que se trata, bajo circunstancias dadas, de un caso de no ver o ignorar humillantes. (Honneth 2011, 169)

La humillación y el menosprecio asumen modalidades gestuales y silenciosas -como la mirada, que -aun cuando no se articulan a través del habla y la palabra- constituye un lenguaje que significa expresiones de violencia. Pues en la efectivización del "ver a través" se suspenden los alcances ético-valorativos de la mirada. Ya no vendría a ser la mirada de "reconocimiento" conforme a la cual el otro individuo es "visibilizado", y que Honneth define en los siguientes términos:

Hacer visible a una persona va más allá del acto cognitivo de la identificación individual, poniéndose de manifiesto de manera evidente, mediante las correspondientes acciones, gestos o mímica, que la persona ha sido tomada en consideración 
favorablemente, de acuerdo con la relación existente; y sólo porque poseemos un saber común de estas formas enfáticas de expresión en el espacio de nuestra segunda naturaleza, podemos ver en su supresión un signo de invisibilización. (Honneth 2011, 169)

Es importante advertir tres aspectos insoslayables conforme a nuestra exposición: (a) Honneth tiene conciencia de dos modalidades de la mirada, una que podríamos denominar "cosificadora", mientras que la otra refiere más bien a la decisión de no mirar a los ojos, aun cuando existe la conciencia de la presencia de quien se mira; (b) ambas modalidades de la mirada estarían fuertemente delimitadas de la mirada enfática de la praxis del reconocimiento, donde esta se determina como un acto valorativo, mientras que las otras no; (c) el autor refiere a "un saber común", cuya existencia permite dar cuenta de que la supresión de las gestualidades enfáticas, de ese tipo de miradas, son un agravio. Ocupémonos entonces de este último aspecto señalado, donde se afincan claramente los supuestos epistémicos de sus planteos.

El "saber común" al que apela Axel Honneth no se trata de un apriorismo sin más, encuentra su fundamento en la génesis misma del sujeto y constituye un punto de anclaje recurrente en su teoría: pues -en última instancia- Honneth siempre se ha visto obligado a recurrir a un enfoque psicológico sustentado, a menudo, en las teorías de la relación objetal elaboradas por Donald Winnicott y Melanie Klein. La fuerza de esa exigencia epistémica viene dada porque la categoría de reconocimiento no es únicamente normativa sino también fuertemente antropológica ${ }^{3}$. Reconstruir todos los argumentos que Honneth aporta a lo largo de su obra sería una enorme tarea para estas páginas, pero daremos algunos indicios.

En "Invisibilidad", la idea viene dada por una evocación directa de la socialización primaria de las personas; pues allí se va conformando un repertorio de identificaciones gestuales como resultado de su interacción con sus referentes primordiales de comunicación e intercambio afectivo, que Honneth comprende bajo el rol materno. Siguiendo a Daniel Stern dice:

El desarrollo socializador en los primeros años de vida se efectúa en la forma de un proceso de regulación recíproca de los afectos y las atenciones, que se lleva a cabo de manera considerable con ayuda del medio de una comunicación gestual: la (maternal) persona de referencia dispone de un amplio repertorio de medios de expresión gestuales y mímicos, que deben dar al niño señales sumamente diferenciadas de su disposición a la interacción; $y$, por el contrario, el niño pequeño dispone

\footnotetext{
${ }^{3}$ Para el estudio de observaciones más detalladas sobre este punto en el pensamiento de Honneth, véase Romero Cuevas (2009; 2013)
} 
Axel Honneth: el conflicto social y los modos de la mirada. Apuntes para pensar el problema más allá del reconocimiento

Jorge Ariel Palacio

de todo un abanico de actividades reflejas que, como reacción a las estimulaciones gestuales de las personas de referencia, se pueden desarrollar formas primeras de un comportamiento social de respuesta. (Honneth 2011, 171).

Son dichas "actividades reflejas" las que construyen el historial del comportamiento gestual introduciendo la clave para comprender y comprenderse en la mirada del otro de manera aprobatoria o despreciativa, proporcionando valor performativo a la praxis del reconocimiento, donde es posible observar "que las expresiones que la acompañan simbolizan formas de reacción necesarias para $<<$ hacer justicia $>>$ a la persona reconocida". (Honneth 2011, 172)

Sin poner el eje en expresiones gestuales o en la cuestión de las miradas, este enfoque es posible encontrarlo en el marco de otras discusiones a lo largo de la obra del autor, pero donde también se remarca el carácter primario y de preeminencia de las relaciones recíprocas de reconocimiento, solo que esta vez orientadas más que nada a fundar la formación de la subjetividad. Honneth, aunque inscripto en el horizonte de la tradición crítica de la Escuela de Frankfurt, ha sido crítico de la asimilación del psicoanálisis que promovieron Adorno y Horkheimer. Honneth interpretó sus estudios entendiendo que para sus predecesores la formación del sujeto estaba sujeta a los imperativos sistémicos predominantes en el orden social, exhibiendo un sesgo monológico importado de lo que él llamó "el paradigma de la dominación de la naturaleza", en el que, al igual que con la naturaleza, los individuos en la familia burguesa son sometidos a la anulación y funcionalización de sus pulsiones, donde la figura del padre encarna los respectivos poderes sociales. Inspirado en Jessica Benjamin, Honneth observa que la psicología social de Adorno no expresa adecuadamente la praxis comunicativa, ni considera los intercambios afectivos que devienen en las relaciones parentales desde donde se satisfacen necesidades de cuidado. Desde esta línea es posible interpretar dicho fenómeno como la preponderancia de una vertiente psicoanalítica donde solamente adquieren significación la trama de relaciones que ejerce el padre.

La teoría de Adorno sólo valora como magnitud comunicativa en el entorno del niño la figura del padre, comprendida como instancia de representación en el seno familiar de la dominación social de la naturaleza; todos los restantes interlocutores comunicativos en la historia de la formación individual quedan para él fuera de consideración; esto es justo lo que le impide subrayar adecuadamente el peso que tiene aquí la interacción social en el proceso; Adorno no tiene en cuenta esa ampliamente expandida esfera de comunicaciones sociales que conforma el marco de los procesos de socialización individuales. (Honneth 2009a, 107)

Queda por preguntarse ¿qué fue lo que la teoría crítica perdió al ganar el espacio epistémico que encontró con Honneth, pudiendo así resguardar de un cierto funcionalismo la comprensión de la interacción social? El rechazo de ingresar en las consideraciones 
Axel Honneth: el conflicto social y los modos de la mirada. Apuntes para pensar el problema más allá del reconocimiento

Jorge Ariel Palacio

psicoanalíticas criticadas, fue clave en la imposibilidad de interpretar las relaciones de poder y las prácticas sociales de menosprecio con mayor robustez epistemológica. Hay en la crítica honnethiana un problemático supuesto de sujetidad que, con el fin de desplazarse de los enfoques monológicos que critica, recae en la asunción acrítica de un normativismo ético que lo lleva visualizar sin rigor teórico el hecho social contrapuesto, pues toda modalidad de interacción social que no pueda circunscribirse bajo la óptica del reconocimiento tiende a interpretarse como una defección, sin encontrar demasiado lugar en la teoría social. Si bien la crítica propugnada por Honneth no deja de ser válida, el posterior desenlace tiende a quitar cualquier remanente de conflictividad en la historia inicial de la psiquis, más aún: también la conflictividad queda asumida como un episodio en la trama de la emergencia del sujeto autónomo como un momento orientado a él, con lo cual todas las operaciones de exclusión y ruptura sencillamente se oscurecen. Modalidades objetivadoras o cosificadoras de la dominación social solo aparecen como lo opuesto al reconocimiento y no se indaga mucho más en ellas.

El enfoque criticado por Honneth está atravesado por un déficit analítico que impide visualizar experiencias de socialización alternativas en las que se destaca el componente intersubjetivo que estructura la personalidad como así también la irrupción de sujetos sociales, pero su posición tiende a instaurar normativamente un horizonte de expectativas morales donde las prácticas sociales que se materializan sin responder a esas expectativas no encuentran mayor visualización teórica que la de conformarse como un espacio excepcional, sin poder ingresar en un camino que podría remarcar el relieve singular que poseen justamente las experiencias de socialización donde las relaciones interpersonales prescinden de tales horizontes normativos, sin por eso agotar su capacidad como productoras de subjetividad.

Otro paso importante en dirección a dicho enfoque psicoanalítico puede encontrarse en el libro que catapultó la fama intelectual del autor: "La lucha por el reconocimiento". Allí, basándose en Hegel, el autor introduce una clave muy similar conceptualmente a lo previamente comentado sobre "Invisibilidad"; pues, al tratar la formación de la identidad individual, sostiene que en dicho proceso se efectúa una modalidad indispensable del reconocimiento: el amor, entendido éste como relaciones primarias de afecto donde uno puede intuirse a sí mismo en su interacción con los otros y, en lo que respecta al desarrollo de la psiquis del sujeto, donde se da lugar a la percepción de sí mismo como individuo. Es en este punto donde apela la teoría de la relación objetal mencionada más arriba. Según dice, en ella encuentra "conclusiones acerca de las condiciones que pueden llegar a una forma lograda de lazo afectivo con otras personas". (Honneth 1997, 118). Y, al mismo tiempo, rechaza "la ortodoxia freudiana" sosteniendo que

[p]ara Freud y sus sucesores los compañeros de interacción del niño habían sido significativos sólo en la medida en que aparecían como objetos de ocupación libidinosa, que resultaban del conflicto intrapsíquico de pretensiones pulsionales incons-

Revista de Humanidades de Valparaíso, 2020, No 16, 215-237

(c) $(1)(9)$ CC BY-NC-ND 
cientes y los controles emergentes del $<<$ yo $>>[\ldots]$ Con ello se establecía un cuadro del desarrollo psíquico del niño, en el que sus relaciones con otras personas solo se consideran como una simple función del desarrollo de tendencias libidinales. (Honneth 1997, 119)

La ausencia de una presencia significativa de los compañeros de interacción ${ }^{4}$ en la formación de la psiquis, estimula en Honneth la elaboración de otra perspectiva en la que la relación monológica entre las pulsiones libidinales y el $<<$ yo $>>$ ceda su centralidad a categorías que justamente remarquen la vitalidad del intercambio recíproco con los otros. La mencionada teoría de la relación objetal ${ }^{5}$ proporciona ese marco:

En ella se introduce la creciente penetración en el valor psíquico de las tempranas experiencias de interacción porque, como complemento para la organización de las pulsiones libidinales, se considera la relación afectiva con otras personas en tanto que segundo componente de estructuración. (Honneth 1997, 120-121)

A esto hay que mencionar la introducción de otro giro psicoanalítico más adelante en su texto "Reificación", donde el autor profundiza la tesis de que el alcance de las tempranas relaciones intersubjetivas llega a fundar la posibilidad de la percepción objetiva. Dicho de otra manera: sin reconocimiento, no hay conocimiento. Esto ocurre por la adopción de la idea de que, con la apropiación de su propia individualidad, impulsada por el reconocimiento de sus interlocutores afectivos, la psiquis gana terreno para la estructuración de sus propias percepciones. Naturalmente, esta idea ya había sido parcialmente esbozada en "La lucha por el reconocimiento", donde, siguiendo a Donald Winnicott, plantea que el espacio que le proporciona al niño su relación de intercambio y dependencia con su madre le permite "aprender a coordinar sus experiencias sensoriales o motoras respecto a un único centro de vivencia y llegar al desarrollo de su esquema corporal". (Honneth 1997, 123). Pero en "Reificación" podríamos decir dichos trazos son abordados con otro espesor.

No entraremos en los detalles de una publicación que reconfigura la noción de "cosificación" acuñada por Marx, y elaborada teóricamente por Lukács, en los términos de la teoría del reconocimiento, pero sí abordaremos la línea argumental desde la que se perciben las tesis hasta aquí mencionadas. En este texto, Honneth sostiene que el reconocimiento es una relación social preeminente, es decir: antecede y conforma una dimensión

\footnotetext{
${ }^{4} \mathrm{O}$ la inexacta representación de los mismos como expresiones de los poderes sociales, como es el caso de la figura paterna mencionada más arriba.

${ }^{5}$ Para Donald Winnicott la idea de "relación objetal" viene dada por lo que él denomina "objetos de transición", donde las cosas, los objetos empíricos, se le presentan a los niños -en su temprano desarrollo- como fuertemente imbuidas libidinalmente, pues a ellos le confieren una carga afectiva que, por primera vez, los mueve hacia una experiencia de posesión, experiencia que, al mismo tiempo, surge como resultado del desapego progresivo de sus cuidadores.
} 
Axel Honneth: el conflicto social y los modos de la mirada. Apuntes para pensar el problema más allá del reconocimiento

Jorge Ariel Palacio

insoslayable para la estructuración de las percepciones y también para la posibilidad de conocimiento objetivo, y para ello cruza la perspectiva que le proporciona la teoría de la relación objetal con planteos provenientes de la psicología evolutiva y dice que:

El niño aprende a vincularse con un mundo objetivo de objetos constantes cuando, desde la perspectiva de una segunda persona, accede al descentramiento progresivo de su propia perspectiva, que en un primer momento es egocéntrica. El hecho de que el lactante comience ya temprano a entrar en contacto comunicativo con su persona de referencia, a reclamar su mirada y a dirigirla hacia objetos cargados de significado, es interpretado por estas teorías como una indicación de la existencia de una fase de ensayo, mediante la que se prueba la independencia de otra forma de mirar el mundo circundante; y en la medida en que el lactante logra colocarse en esta segunda perspectiva y percibir el mundo desde ella, poseerá la instancia correctiva que le permitirá por primera vez una representación de los objetos despersonalizada, objetiva. (Honneth 2007, 63).

Es justamente aprendiendo a situarse en la perspectiva de un compañero de interacción que los niños aprenden a constatar algo, a ser conscientes de algo, que está fuera de ellos y cuya palpabilidad emerge de los indicativos que proporcionan la mirada de otro, pero al mismo tiempo, es justamente allí donde su propia mirada encuentra validez y realidad. Como hemos podido ver, la experiencia de la confirmación de nuestra propia persona en la persona del otro es un momento de vital importancia en la constitución del sujeto, algo que cada uno arrastra consigo y proporciona los marcos interpretativos capaces de producir un saber mediante el cual puede leerse el maltrato, el desprecio, como no-reconocimiento. De hecho, es importante ver, según Honneth, como desde nuestra temprana historia individual el intercambio de miradas $\mathrm{y}$, sobre todo, de miradas que simbolizan una apertura hacia la aceptación de nosotros por parte de los otros, predetermina la obtención de la mirada propia sobre el mundo. Con esto podemos observar que Honneth, al mismo tiempo que reconstruye la trama de la historia psíquica e instaura en sus inicios la conformación de un "saber" que permite reconocer el valor performativo de las experiencias de intercambio intersubjetivo, como la mirada. También bajo este despliegue desata una serie de operaciones que tienden a des-conflictivizar la mencionada trama dando como resultado una interpretación de los modos gestuales y de la mirada que sólo se establece como correlato del reconocimiento, sin mayor indagación en dichas experiencias. Tales operaciones son un universal presupuesto de sujetidad, y es que, ¿todos somos sujetos de la misma manera?, pero también, complementariamente, una norma de sujetidad. Por otro lado, como mencionamos previamente, el cambio de perspectiva psicoanalítica adoptado aparta de sus consideraciones lo que el sujeto deja tras de sí al constituirse como tal. Entendemos que hay en ese proceso indicios de las exclusiones, negaciones y represiones que lo sostienen y que sostienen también su vínculo con el mundo, que el marco del reconocimiento no problematiza por delegar en expectativas de efectivización de reco-

Revista de Humanidades de Valparaíso, 2020, No 16, 215-237

(c) $(1)(9)$ CC BY-NC-ND 
Axel Honneth: el conflicto social y los modos de la mirada. Apuntes para pensar el problema más allá del reconocimiento

Jorge Ariel Palacio

nocimiento futuro, orientadas hacia adelante, donde lo no integrado puede ser integrado. El señalamiento no cobra su importancia por la mera posibilidad percibir otro encuadre, sino porque produce consecuencias para la teoría política y social y, en este caso, para el abordaje de la mirada como fenómeno político y social.

\section{Más allá del reconocimiento}

El reconocimiento, como lo piensa Honneth, supone la vuelta al ruedo de las relaciones político-jurídicas donde se cristalizan pautas intersubjetivas que proyectan sobre el comportamiento de las personas el índice que les permite visualizar la aceptabilidad moral de sus prácticas, conformando lo que Honneth denomina un "otro generalizado", una especie de esfera simbólica que estabiliza las tensiones sociales, no las agota, y cuya ruptura produce las condiciones para la "lucha por el reconocimiento". De este modo, la conflictividad social tropieza con una "gramática moral" desde la que se puede hacer una lectura de las disputas que entablan los diversos actores sociales.

Así y todo, resulta menester no ya pensar en los términos de esa conflictividad inscrita en el seno de la dialéctica del reconocimiento, sino en modalidades del conflicto social que supongan la suspensión de esa dinámica. No referimos a una situación donde se suspenden las disputas, por el contrario: hablamos de una suspensión desde donde resultan pensables los conflictos más profundos. En este punto la lógica del reconocimiento propuesta por Honneth encuentra obstáculos estructurales que no puede visualizar porque se ve condicionada por el presupuesto de una idea de eticidad, donde los enfrentamientos sociales que se producen impactan sobre la experiencia que poseen los sujetos involucrados en la necesidad de re-armar el entramado de relaciones que los alberga para construir nuevas formas de solidaridad institucionalizadas en el derecho. Hay para el autor alemán una hipótesis recursiva de racionalidad inscripta en el seno mismo de la lógica del reconocimiento, donde se introduce la expectativa de ampliar en términos evolutivos las limitaciones que otrora la crítica destacaba. Honneth impulsa la idea de que las producciones del ser humano van instituyendo formas progresivas de racionalidad (ampliaciones de las relaciones de reconocimiento) que se sostienen como parámetro analítico desde el cuál se destaca lo que es ajeno, y no ingresa en el derrotero de dicha lógica, como realidad excepcional, reacia a ser pensable en sus singularidades como componente de un orden social. El problema está en que los fenómenos de dominación social incluyen también entre sus mecanismos modalidades radicales de exclusión y abyección social: espacios producidos para la habitabilidad de determinados cuerpos, formas de ciudadanía y criterios de civilidad que fijan límites y consolidan normas cuyo potencial performativo apuntala la admisibilidad de los sujetos sociales y conforman mecanismos cuya profundidad excede el simple hecho de ser el costado no alcanzado de la racionalidad (cf. Honneth, 2009b, 60-61) 
Axel Honneth: el conflicto social y los modos de la mirada. Apuntes para pensar el problema más allá del reconocimiento

Jorge Ariel Palacio

Apelar sólo al reconocimiento en el marco de escenarios conflictivos, nos demandaría una re-elaboración política de lo social tal que las posiciones dominantes deberían des-hacer su lugar como actores de privilegio, reconociendo y evidenciando al mismo tiempo la violencia que los sostiene, retirando así el mantra de naturalidad con el que recurrentemente se justifican las asimetrías sistémicas productoras de sujetos dominantes, sujetos en posición de subordinación, pero también sujetos en posición de subordinación repudiados y excluidos, cuerpos expulsados.

Recurrir en este punto al enfoque de Honneth resulta insuficiente, pues debemos prescindir, para pensar la singularidad de los hechos, tanto del reconocimiento en sí, como de las expectativas de reconocimiento, no por una falta de verdad en esa idea, sino porque colocarla como horizonte de interpretación permanente oscurece dimensiones igual de fundamentales de la conflictividad social y nos impide esclarecer otras articulaciones de la mirada que no pasan justamente por reconocer. Hablaremos entonces de la mirada objetivadora (2. 1) y de la mirada abyecta (2.2)

\subsection{Mirada objetivadora}

Previamente dijimos que Honneth, en "Reificación", reparó en torno al problema de la mirada cosificadora y atribuyó su existencia a la intervención de prejuicios y/o estereotipos sobre los que se emplaza una particular negación del reconocimiento conforme a la tipología del menosprecio que él mismo previamente estableció en "La lucha por el reconocimiento" (cf. Honneth 1997, 160-175). Honneth entiende que hay una mirada identificatoria que remite al carácter solamente cognitivo por medio del cual se constata algo que previamente ha sido conocido. Según él, es un acto identificatorio que, a diferencia del reconocimiento, no abre un espectro de valoraciones a través del cual es posible encontrar estructuras axiológicas. Se presenta como una práctica despojada de contenido ético, cuyo alcance es contrapuesto al del reconocimiento. Es justamente por un relativo desprecio al otro que quien mira de esa manera lo hace quitándole al otro cualquier posibilidad de afirmación valorativa frente a él, como si fuese un objeto más. La pregunta es ¿cómo se estructura esa mirada? ¿Y qué características asume esta modalidad de interacción social donde el reconocimiento pareciera interrumpirse? Más allá de la categoría de "desprecio", "menosprecio", la historia de Occidente ha dado experiencias de objetivación o cosificación social que parecieran no poder agotarse apelando a dichos significantes morales, ya que señalan relaciones que transcurren donde hay institucionalizadas formas de sociabilidad que delimitan las fronteras donde imperan relaciones intersubjetivas, entre actores sociales cuyo estatuto como sujetos es un hecho, y relaciones donde ese estatuto es ambiguo. En este contexto hablar de la cosificación u objetivación ${ }^{6}$ como modalidades

\footnotetext{
${ }^{6}$ Es también este presupuesto desde donde analizaremos los fenómenos involucrados con la "mirada abyecta"
}

Revista de Humanidades de Valparaiso, 2020, No 16, 215-237 
Axel Honneth: el conflicto social y los modos de la mirada. Apuntes para pensar el problema más allá del reconocimiento

Jorge Ariel Palacio

del desprecio, presupone una expectativa implícita de apertura hacia otras posibilidades relacionales, pero no destaca la cotidianidad vivencial en las que esas expectativas no son claramente deducibles ni dilucidables. Recurriremos entonces a otros enfoques epistémicos que abordan el problema de la mirada sin asumir tales presupuestos normativos.

Por ello es destacable incorporar el punto que une a autores que, en apariencia, son tan disímiles y provienen de tradiciones de notable diferencia, pero cuyas producciones teóricas se han hecho eco de otras experiencias históricas en las que la idea de "humanidad" fue jaqueada, ingresando en una crisis casi irreparable. Tanto los campos de concentración, como el colonialismo, el racismo, el antisemitismo y también el poder disciplinar que actúa a través de las instituciones penitenciarias, suspenden la pretensión de universalidad de todo humanismo, son la sustancia concreta de lo que Giorgio Agamben caracterizó como "estado de excepción", y producen una mirada en la que el otro es construido no solamente como cosa, sino también como vida desnuda. Dicha mirada se funda en el dominio efectivo que determinadas relaciones sociales hegemónicas tienen a lo largo de la modernidad, en donde se evidencia que la universalidad de lo humano se sostiene mediante una tensión dialéctica en la que la diferencia se asimila o se destruye, imposibilitando la emergencia de su ser singular, y sometiendo a los otros al entramado de las taxonomías y jerarquías que fundamentan la dignidad humana como atributo exclusivo de una cultura o clase, y reduce a mera naturaleza todo aquello que considera exterior, incluso la completa multiplicidad de la vida natural.

Si bien el abordaje que realiza Sartre en "El ser y la nada" sobre la mirada, no posee resonancia política de otros ensayos, no por eso la anatomía de las sensibilidades puestas en juego debe ser ignorada. Sartre describe una escena en donde emerge la pregunta por la que nosotros también interrogamos:

Estoy en una plaza pública. No lejos de mí hay césped y, a lo largo de él, asientos. Un hombre pasa cerca de los asientos. Veo a este hombre, lo capto a la vez como un objeto y como un hombre. ¿Qué significa esto? (Sartre 1996, 282).

E inmediatamente responde:

Si debiera pensar que no es sino un muñeco, le aplicaría las categorías que me sirven de ordinario para agrupar las cosas espacio-temporales [...] Lo captaría como situado junto a los asientos, a dos metros veinte del césped, ejerciendo cierta presión sobre el suelo, etc. [...] Podría hacerlo desaparecer sin que las relaciones de los otros objetos entre sí quedaran notablemente modificadas [...] Percibirlo como hombre $[. .$.$] es captar una relación no aditiva entre el asiento y él, es registrar una$ organización sin distancia de las cosas de mi universo en torno a ese objeto privilegiado [...] Se trata de una relación sin partes [...] en cuyo interior se despliega una espacialidad que no es mi espacialidad. (Sartre 1996, 282)

Revista de Humanidades de Valparaíso, 2020, No 16, 215-237

(c) (1) (9) CC BY-NC-ND 
Si se trata de un objeto o se trata de un ser humano, las diferencias resultantes para la conciencia que percibe son evidentes y, más allá de las múltiples críticas realizadas a Sartre, la cita mencionada deja explícita una estructura fundamental que configura la conciencia y cuyas características se articulan con la mirada: el hecho de "constituir". Según tales consideraciones, una cosa como el pasto guarda una relación aditiva con el resto de su entorno porque "se comporta" como habiendo sido colocado en ese lugar y bajo esa modalidad se agota toda su latencia. Lo contrario ocurre si la mirada se arroja sobre ese "objeto privilegiado" que, conforme a estas consideraciones, es el ser humano. En ese caso, la mirada remite a un encuentro que excede por completo la forma aditiva y ostenta una modalidad que se iguala a mi mirada, pues el cruce ya no está dado por la unilateralidad de mis percepciones, sino que estas, simultáneamente, transcurren siendo interpeladas por la presencia de algo que orienta el posicionamiento de los objetos hacia él mismo de la misma manera que ocurre con mi conciencia. El prójimo es, ciertamente, entre sus posibilidades, un objeto para mí, pero también un sujeto que puede arrojarme a mí al hecho que constituye su mirada, a "ser visto por él" (cf. Sartre 1996, 285). Dicho por Sartre de una manera que resume a la perfección nuestras interpretaciones: "el ser humano se define con relación al mundo y con relación a mí [...] es el sujeto que se me descubre en esa huida de mí mismo hacia la objetivación" (Sartre 1996, 285). Y es esa huida de mí mismo hacia la objetivación la que se pone en juego a través de la mirada. Pues, así como Sartre remarca miradas que se encontrarían en un mismo plano, concomitantemente aparece el peligro, la irrupción del hecho de que yo también puedo devenir objeto de la mirada y el juicio ajeno. Incluso el peligro mismo se describe como la estructura del "ser-para-otro": esa mirada me descubre como objeto de posibilidades que no son propias, soy una tabula rasa cuya vida se ahoga entre los murmullos de los otros y mi existencia se degrada como objeto "para-otros". El francés refiere esta degradación también a la vergüenza y a la sensación de desnudez que de ella deviene: "la vergüenza es el sentimiento de estar caído en el mundo, en medio de las cosas, y de necesitar la mediación ajena para ser lo que soy" (Sartre 1996, 316).

Estas ideas no deben ponderarse únicamente como una simple descripción fenomenológica, tras ellas es posible desarticular modalidades silenciosas y gestuales en torno a las cuales se cristalizan en la cotidianidad las relaciones de poder. Y si bien hasta acá el texto elaborado por Sartre no introduce la temática, de él es posible extraer tensiones orientadas en esa dirección: la mirada policial, por ejemplo, que se dispone a realizar una pesquisa con el fin de investigar sobre una denuncia, no admite un intercambio según el cual la mirada del otro lo sustraiga de su condición de sujeto; improvisando gestos filosos e imperturbables, su ejercicio es plenamente identificatorio y si en algo ocurre eso que Honneth denomina reconocimiento, la forma del mismo prescinde completamente de la presencia activa del otro y se produce nada más y únicamente en la conciencia del oficial bajo las múltiples corroboraciones que intervienen luego de un interrogatorio. Ocurre lo que el filósofo Agamben denomina "identidad sin persona", en donde la identidad del 
Axel Honneth: el conflicto social y los modos de la mirada. Apuntes para pensar el problema más allá del reconocimiento

Jorge Ariel Palacio

sujeto se desplaza del campo de las prácticas de reconocimiento. La "humanidad de lo humano" ya no se configura en torno al carácter singular e irreductible del ser del otro, sino a los datos identificatorios en el que queda abolida toda multiplicidad. Esta lógica falsea el "dispositivo de la persona" y a la vez que suspende su registro epistémico-visual, muestra su imposibilidad como "universal".

Lo que ahora define mi identidad y permite reconocerme son los arabescos insensatos que mi pulgar teñido de tinta ha dejado sobre una hoja en un destacamento de policía. Es decir, algo de lo que no sé absolutamente nada, con lo cual y por lo cual no puedo identificarme de ningún modo ni tomar distancia: la vida desnuda, un dato puramente biológico. (Agamben 2011, 73)

Ese "algo de lo que no sé absolutamente" que señala Agamben, revela un aspecto nodal de la mirada objetivadora. Quien se sitúa frente a ella pareciera no poner nada de sí más que aquello que la mirada del otro ve en él como destacable, en este caso para identificarlo, pero en todo caso cancelando cualquier otra posibilidad que a él refiera. La destacabilidad de quien es observado, naturalmente, ya ha sido depositada en él y lo define. Fanon habla desde su propia experiencia racializada y describe su ingreso al colectivo, donde las miradas se le vienen encima: "Estoy sobredeterminado desde el exterior [...] Ya las miradas blancas, las únicas verdaderas, me disecan. Estoy fijado. Una vez acomodado su micrótomo realizan objetivamente los cortes de mi realidad" (Fanon 2009, 115). Y mientras quien es mirado es disecado, fijado, diseccionado, el sujeto de esa(s) mirada(s) rehúye a la individualización. "Se trata de una realidad impalpable, fugaz y omnipresente, que realiza frente a nosotros a nuestro Yo no revelado y que colabora con nosotros en la producción de ese Yo que nos escapa" (Sartre 1996, 309). No hay congruencia del saber que cada uno posee sobre el otro, la mirada objetivadora se recuesta bajo la pretensión de saber todo lo que quiere saber sobre aquél a quien mira. Mientras que, al mismo tiempo, intenta ubicarse fuera del alcance del saber de quien es mirado, aun cuando este pueda mirarlo, sin que su mirada tenga valor alguno. Algo de la economía visual de la "mirada normalizadora" que Michel Foucault atribuye al panoptismo del siglo XVIII persiste en esta lógica: "se ejerce haciéndose invisible y, por el contrario, impone a aquellos a quienes somete a un principio de visibilidad obligatoria" (Foucault 2008, 218).

\section{2. Mirada abyecta}

En una conferencia dictada por Silvia Rivera Cusicanqui (2016), la autora aimara menciona experiencias recolectadas a través de la etnografía entre las que es posible detectar modulaciones cotidianas y silenciosas en torno a las que se forja lo que ella denomina "indianización", que no se determina únicamente en torno a la etnicidad, sino también en torno a la asociación que el imaginario racial dominante traza entre ella y la división social del trabajo. Según expresa su relato, las mujeres que se desempeñan como empleadas

Revista de Humanidades de Valparaíso, 2020, No 16, 215-237

(c) (1) (9) CC BY-NC-ND 
Axel Honneth: el conflicto social y los modos de la mirada. Apuntes para pensar el problema más allá del reconocimiento

Jorge Ariel Palacio

domésticas se sumergen al interior de experiencias interpersonales en las que es posible detectar un rasgo característico de las prácticas racistas, sean ellas blancas o indígenas: el no mirar a los ojos a la persona que se contrata. Obviamente, el reparo de su presencia está dado por la constatación que proporciona cierta mirada, pero dicha mirada no las interpela de manera tal que pueda interpretarse como un intercambio latente; tampoco -al menos en el recorte proporcionado por la situación especificada- dicha mirada refiere únicamente a una voluntad de sometimiento:

Ser sirviente doméstico te indianiza, así seas blanco. He tenido una estudiante que decidió hacer su tesis sobre el trabajo doméstico en los hogares de clase media. Se metió como empleada doméstica y fue indianizada inmediatamente. ¿Eso qué quiere decir? Que ya no la miraban, era como una transparencia por la que pasaba la mirada del otro. (Rivera Cusicanqui 2016, 78)

El comentario de Cusicanqui está situado en el marco de tensiones/conflictos raciales y de clase estructurales para muchas sociedades modernas, en este caso la boliviana, dicha condición es la realidad que atraviesa y constituye esos modos de mirar ${ }^{7}$. Consecuentemente, la dialéctica del reconocimiento queda aquí suspendida. Aunque el reparo de la presencia de la otra persona ocurre, ella siente una resistencia a ser enfrentada con la mirada, no puede ser asumida como quien/lo que está allí adelante. Es como si se la arrojase obstinadamente fuera del campo visual. El hecho es paradójico, ya que al mismo tiempo quien mira, si bien alcanza a percibir con la mirada, expulsa inmediatamente de su mirada lo que mira. Es una mirada abyecta. Oportunamente, debemos advertir que, en la situación mencionada, aun cuando el contacto visual es eludido, esto ocurre en un lugar donde quien toma esa decisión, en principio, tiene el control, es el/la dueño/a de casa, y hace valer su posición de dominio despojando la presencia de la otra persona de comunicación visual. Es una modalidad de la mirada abyecta donde quien la ejerce lo hace poseyendo pleno dominio del territorio en cuestión.

La abyección, como comenta la filósofa Julia Kristeva en su libro "Poderes de la perversión":

\footnotetext{
${ }^{7}$ Aunque planteado así parezca una generalidad, no ingresaremos en mayores complejidades sociológicas acerca de los regímenes de poder mencionados. Aquí el objetivo solamente atenderá a una esfera micropolítica/molecular donde las tensiones estructurales/molares producen nudos y afincamientos que se proyectan en el comportamiento, la mirada para este caso, de determinados sujetos sociales.
}

Revista de Humanidades de Valparaíso, 2020, No 16, 215-237 
No tiene, en realidad, objeto definible. Lo abyecto no es un ob-jeto en frente de mí, que nombro o imagino. Lo abyecto no es mi correlato que, al ofrecerme un punto de apoyo sobre alguien o sobre algo distinto ${ }^{8}$, me permitiría ser más o menos diferenciada y autónoma. (Kristeva 1989, 8)

Lo que es abyecto introduce un desequilibrio radical, destempla los afectos de quien mira, ya que, si bien coloca en el destierro visual la presencia del otro, al mismo tiempo se siente llamado por ella: alguien está allí y la opacidad de su figura se muestra insistente, presiona desde un "afuera" borroso la centralidad óptica del sujeto: está, pero no está.

El reconocimiento aquí queda abolido tras la imposibilidad de encontrar al otro como sujeto y de percibirlo como tal: no hay allí intercambio, ni tan siquiera espacio físico, abierto por la mirada, que dé al otro la posibilidad de expresarse, aun cuando exista el percato de su presencia. Pero la posibilidad de encontrar al otro objetivado, también es cuestionable: diríamos que, si la mirada objetivadora o cosificadora ostenta la pretensión de penetrar incisivamente la presencia del otro y asumirlo solamente desde sí, como un objeto o cosa, la "mirada" abyecta no le otorga a quien es percibido el privilegio de ser mirado, menos aún de colocarse frente a su mirada.

También aparece la experiencia de la incomodidad, o de lo incómodo; la experiencia de un acercamiento en el que la sensibilidad expresa alteración frente a lo que se muestra ante los sentidos de quien mira como ocupando lugar, como un remanente, residuo cuya presencia interrumpe la serenidad unívoca de su orden. La mirada abyecta es esquiva, evita contacto visual con el otro, remite, en esta situación, a que en ese contexto la posibilidad de la distancia ya es imposible, aunque más no sea de manera provisoria. Y quien a menudo goza del privilegio de mirar, de controlar, ahora se encuentra habitando lo que considera su propio espacio con alguien a quien no le corresponde ejercer la mirada, pero que está ahí y puede mirarlo también. La mirada abyecta, el no mirar, o "el mirar a través", como la llama Honneth, es el intento obstinado por ignorar eso que ocurre. Es como si al declararse impotente la mirada que presume sujetos y objetos, esta deviniese en una mirada que pretende ignorar la presencia de lo que sabe. Entre la plena reducción visual de una hacia el "no ver lo que se siente" de la otra, hay fisuras: aquello que comienza a exceder los límites de lo que se domina, y comienza a habitar el espacio que "no le pertenece", no se mira, o se mira de costado, o se le da la espalda, como manera de negar una cierta igualdad momentánea y ficcional, y como manera de negar el "privilegio" de una mirada de reconocimiento.

Esta ambivalencia de percibir, pero no mirar como parte de una misma estructura de comportamiento, es interrogada por Fanon desde la experiencia de la racialización.

\footnotetext{
${ }^{8}$ Nótese en este punto la marcada diferencia que esta relación plantea respecto de la teoría del reconocimiento de Honneth, donde los compañeros de interacción y los objetos le abrían al sujeto la posibilidad de su autopercepción individual y diferenciación respecto de lo que le es externo
} 
Axel Honneth: el conflicto social y los modos de la mirada. Apuntes para pensar el problema más allá del reconocimiento

Jorge Ariel Palacio

Fanon relata cómo la mirada racializadora anula cualquier posibilidad de su ser. Su apariencia lo determina desde el exterior y se agota completamente como hecho constatado por la mirada de los otros, blancos. Pero esa mirada convive a su vez con una percepción sobredimensionada de su cuerpo a través de la cual se siente la incomodidad esquiva de los otros:

En el tren, no se trataba ya de un conocimiento de mi cuerpo en tercera persona, sino en triple persona. En el tren, en lugar de una, me dejaban dos, tres plazas. Ya no me divertía tanto. Ya no descubría las coordenadas febriles del mundo. Existía triple: ocupaba sitio. Iba hacia el otro [...] y el otro evanescente, hostil, pero no opaco, transparente, ausente, desaparecía. La náusea... (Fanon 2009, 113)

El ocupar espacio es quizá la muestra de un desajuste entre lo que detenta la significación y el sentido que estructuran y abren un mundo y aquello que, habiendo sido expulsado como condición para la emergencia de un mundo, está habitando el mundo: "el mundo es su propio rechazo, el rechazo del mundo es el mundo" (Nancy 2003, 75).

\subsubsection{Imágenes de la abyección}

En los versos del joven poeta César González resuena aquel desajuste que configura los espacios territoriales donde se despliega la exclusión social en la provincia de Buenos Aires: "La avenida es una frontera que divide a la villa del mundo. Los rezos ruegan el milagro de exiliarse a la sociedad". (González 2020, 56).

En la mirada abyecta, la sujetidad de quien mira, de quien percibe, es también puesta entre paréntesis. La soberanía de su plena afirmación perceptiva se desploma, no hay control, algo lo incomoda: eso que se niega a mirar dice algo de él. Y es que aquel a quien su mirada esquiva, pareciera ser ininteligible para él, pero ofrece la evidencia que muestra los límites de sus propias condiciones de sociabilidad. Lo que no se puede mirar no es, únicamente, porque ha sido estrictamente negado, sino también repudiado, forcluído, su "ausencia" constituye los bordes de su sujeción, abre el espectro de lo que no ha podido ser totalmente integrado entre sus propios registros visuales y sensibles, y su reaparición, su constatación, produce conflictos in-absorbibles desde la dialéctica del reconocimiento. Es la emergencia del fenómeno psicótico en el seno mismo de lo social, pues el control se expresa como un mecanismo inviable. El otro se hace presente bajo diferentes condiciones de la experiencia social: su presencia se expresa como metáfora de quien nunca lo reconoció; los fantasmas del destierro reaparecen, y lo que antes no se quiso mirar, ahora comienza a alucinarse.

El cuerpo de estas experiencias es la historia misma de la cultura occidental, aunque también, de manera recurrente, de la cultura nacional argentina, donde se acumulan gran cantidad de acontecimientos históricos en los que resultan rastreables estas prácticas. El

Revista de Humanidades de Valparaíso, 2020, No 16, 215-237

(c) (1) (9) CC BY-NC-ND 
Axel Honneth: el conflicto social y los modos de la mirada. Apuntes para pensar el problema más allá del reconocimiento

Jorge Ariel Palacio

racismo cuelga sobre sus espaldas las modalidades más profundas de abyección social. El célebre epíteto: "el aluvión zoológico", con el que, por parte de las clases dominantes, se caracterizó un acontecimiento histórico en la Argentina, representa el acto de nombrar esa forclusión. El "lenguaje zoológico" del que habla Fanon $(2015,37)$ no solamente alude a la permanente animalización en la que incurre el colono sobre el colonizado, sino que también es la acción que emana tras el temor de que en el deseo del otro resida el querer ocupar un lugar que desde la perspectiva del colonizador no le corresponde: "quieren ocupar nuestro lugar", dice el colonizador (Fanon 2015, 34).

Las representaciones del terror también están fuertemente emparentadas con la mirada abyecta, no es casual que entre los estereotipos más utilizados dentro de la literatura y las producciones artísticas que allí se ubican, la figura del "monstruo" sea casi fundacional. Michel Foucault entiende dicho tópico como una producción discursiva de la emergencia de nuevas relaciones de poder en la Europa de finales del siglo XVIII que dan fruto a una noción de normalidad articulada - por un lado- en la creación de nuevas formas de castigo y corrección: el encierro como ámbito de aplicación de la punición, pero también -por otro lado- la producción de una nueva economía sexual y moral anclada en tres figuras límites para el imaginario de la naciente socialidad moderno-europea: la homosexualidad, el incesto y la antropofagia (cf. Foucault 2000, 83-106). Se constituye como monstruo a todo aquel que se visualiza como rompiendo esa franja que separa el orden social de la vida natural y salvaje. En ese sentido, el filósofo francés habla de un "monstruo de arriba" y un "monstruo de abajo", ambos destructores del contrato social: el déspota y el bandolero ${ }^{10}$. También ambos representados justamente como quienes llevan a cabo comportamientos repudiables: actos espectaluzarizados de violencia, desenfreno sexual, violación de las reglas del parentesco, parricidio. En este sentido resuena la posterior construcción del modelo edípico para la interpretación de la psiquis como deudora de las imágenes mencionadas: el rey que se arranca ni más ni menos que los ojos al corroborar el cumplimiento de su destino.

Pero el desenlace del significante "monstruo" no solo se limita a habitar los registros discursivos mencionados, también ha sido una recurrente metáfora política en torno a la cual se construye una representación alucinada del otro sometido. Es una instancia diferente a la simple mirada esquiva que comentamos al principio, o a la modalidad de la

\footnotetext{
${ }^{9}$ De tal metáfora se apropiaron las élites dominantes porteñas para describir, con rechazo, las movilizaciones populares que llegaron a Plaza de Mayo pidiendo por la liberación del coronel Juan Domingo Perón el 17 de octubre de 1945. No obstante, se sabe que quien acuñó dicha expresión fue Ernesto Sanmartino, político y militante de la Unión Cívica Radical. El hecho fue posterior al 17 de octubre del ' 45 y se produjo, siendo Perón presidente, en una sesión de la Cámara de Diputados en junio de 1947. La metáfora fue utilizada contra diputados del bloque peronista.

${ }^{10}$ Quien a menudo es considerada como fundadora del género terror reúne entre sus historias justamente las figuras mencionadas. Ejemplos clásicos lo constituyen "Lo Misterios de Udolfo", un personaje de la familia real capaz de los crímenes más horribles perpetrados con la ayuda de bandoleros que trabajan para él.
}

Revista de Humanidades de Valparaíso, 2020, No 16, 215-237 
Axel Honneth: el conflicto social y los modos de la mirada. Apuntes para pensar el problema más allá del reconocimiento

Jorge Ariel Palacio

abyección que sucede a la incomodidad que suscita la presencia del otro; aquí se elabora fantasmáticamente al otro y se configuran imágenes que producen un modo de relacionarse con los otros.

Si bien los usos de la monstruosidad en la Argentina como calificativo de las clases populares poseen un derrotero muy complejo presente a lo largo de su historia, los desenlaces vinculados a las experiencias socio-culturales que surgen luego de la emergencia del peronismo, sobre todo luego de 1945, son un documento ostensible, justamente porque remarcan el impacto que produjo ante la mirada de los sectores dominantes blancos y burgueses la aparición de una realidad social cuyo reconocimiento había sido repudiado y ahora aparecía subvirtiendo los límites del paisaje urbano. Aquellos a quienes obstinadamente nadie miraba, "invadieron" la ciudad porteña: "parecía una invasión de gentes de otro país" (Martínez Estrada 2005, 55), "fue la violenta y desnuda presentación de una nueva realidad humana [...] la ciudad los vio con la misma aprensión con que vería a los marcianos" (Luna 1971, 273), "nosotros no sabíamos que esa multitud existía" (Sivak $2005,123)$, todas expresiones que relatan desconocimiento, pero que al mismo tiempo muestran dificultades de inteligibilidad social y permiten visualizar la sensación de temor frente al desgarro repentino de la normalidad del espacio público, esta vez ocupado y en disputa con un rostro que no es el propio, cuyo "reconocimiento" ocurre alucinatoriamente nombrándolo en clave metafórica desde un espectro semántico que alude a las formas de la vida animal o extraterrestre que asaltan el espacio humano. En una de las primeras publicaciones del -en aquel entonces- joven escritor argentino Julio Cortázar, "Bestiario", de 1951, se destaca sustantivamente la idea de monstruosidad, sobre todo en su cuento "Las puertas del cielo", donde el personaje principal dedica un tiempo considerable a reflexionar sobre "los monstruos" y detalla obsesivamente sus singularidades fenotípicas y sus olores, pero también incurre en descripciones que muestran similar sensibilidad a las metáforas mencionadas previamente, los monstruos que bailan en la milonga "se asoman con las once de la noche, y bajan de las zonas vagas de la ciudad" (Cortázar 1969, 129), vienen de otro lugar, remarcan un contraste frente a los habituales intercambios donde se desempeña la voz principal, son otros seres.

Las metáforas con las que el ensayista Domingo F. Sarmiento (2007) expresa las tensiones que atraviesan la realidad nacional en el siglo XIX argentino otorgan testimonio de este mecanismo: la descripción de la población gauchesca se realiza utilizando imágenes que pretendidamente representan las culturas del norte africano y del continente asiático (Olalla, 2007, 192). La "cultura oriental" previamente mediada en el discurso de Sarmiento por la palabra del colonialismo inglés y francés, se enarbola como un código a través del cual la "barbarie" local se traduce en los términos en que la "civilización" euro- 
Axel Honneth: el conflicto social y los modos de la mirada. Apuntes para pensar el problema más allá del reconocimiento

Jorge Ariel Palacio

pea ha constituido como "barbarie" a las culturas por ella sometidas". Aquí las imágenes que proporciona Sarmiento no son las de una aproximación temerosa, sino que más bien hay inscriptas en ellas una cierta fascinación por algo que se presenta como exuberante y sublime. No está lejos de esta forma de fascinación el respeto que impone, según Kant, lo sublime como algo donde "nuestra imaginación evidencia sus barreras y su falta de adecuación" (Kant 2003, 215). En este sentido, ante esa falta de adecuación que impone lo sublime, la sublimación se presenta como una operación en virtud de la cual lo que es abyecto ya no se esquiva, ya no se evita, sino que se lo apropia: "La sublimación... no es otra cosa que la posibilidad de nombrar lo pre-nominal, lo pre-objetal, que en realidad sólo son un trans-nominal, un trans-objetal" (Kristeva 1989, 20).

\section{Consideraciones Finales}

En el transcurso del presente escrito abordamos cómo se resuelven determinadas formas de conflictividad social en el marco de determinados comportamientos sociales como pueden ser la mirada y las formas consecuentes de representación. Partimos de Axel Honneth por entender que la teoría del reconocimiento conforma un puente clave que une la cuestión de las miradas con la conflictividad social, pero a la vez, tomando como referencia sus análisis, ampliamos el espectro de las consideraciones sobre los modos de mirar a los que se dedica el autor, entendiendo que al abordaje que hace presupone normativamente que las tensiones y disputas sociales tienden a encontrar un desenlace resolutivo en la materialización de formas de reconocimiento. Esta hipótesis mostró su confirmación en dos aspectos claves destacados: un modelo de comprensión de la personalidad anclado fundamentalmente en experiencias intersubjetivas de reconocimiento que se postulan como parámetro moral y una lógica de tipo evolutiva que deposita en la realización de relaciones de reconocimiento mutuo la expectativa de resolver formas de sociabilidad no recíprocas, lo que desatiende la especificidad de comportamientos vinculados a formas de dominación y del poder por visualizarlos como una excepción y no como un componente social.

Tratando de apelar a la especificidad esos comportamientos, intentamos profundizar en torno a las articulaciones concretas de un modo de mirar (objetivador) que se recuesta sobre una presunción de visualización absoluta del otro; como así también, en torno a las especificidades de un modo de mirar (abyecto) en el que se le niega "el privilegio" de la mirada al otro. Sobre este último punto, desembocamos en un mecanismo que consiste en darle un nombre, una representación, a aquello que no se quiere mirar, a aquello que incomoda.

\footnotetext{
${ }^{11}$ Considerando lo dicho más arriba, es interesante notar que muchas de las representaciones utilizadas en los discursos orientalistas hacen uso de la idea de un predominio despótico en Oriente. Sin ir más lejos, Hegel plantea que en los pueblos orientales el espíritu se materializa en la voluntad de una sola persona (cf. Hegel 1970, 126).
}

Revista de Humanidades de Valparaiso, 2020, No 16, 215-237 
Axel Honneth: el conflicto social y los modos de la mirada. Apuntes para pensar el problema más allá del reconocimiento Jorge Ariel Palacio

Partiendo de un problema planteado por Honneth, pero suspendiendo el alcance de su presuposición más fuerte, la del reconocimiento, dimos con una visión más amplia para el estudio de la mirada como comportamiento social, y pudimos ver cómo, abandonando el horizonte del reconocimiento, existen relaciones que se configuran bajo una nula expectativa de sociabilidad recíproca, a punto tal que es posible despejar desde el análisis de la mirada abyecta modos a través de los cuales se conforman experiencias de dominación donde los otros son producidos e imaginados de forma unilateral.

\section{Referencias bibliográficas}

Agamben, Giorgio (2011). Desnudez. Buenos Aires: Adriana Hidalgo.

Cortázar, Julio (1969). Las puertas del cielo. En: Cortázar, Julio, Bestiario, pp. 117-138. Buenos Aires: Editorial Sudamericana.

Cortázar, Julio (1951). Bestiario. Buenos Aires: Editorial Sudamericana.

Fanon, Franz. (2009). Piel negra, máscaras blancas. Madrid: Akal.

Fanon, Franz (2015). Los condenados de la tierra. Buenos Aires: Fondo de Cultura Económica.

Foucault, Michel (2000). Los anormales. Buenos Aires: FCE.

Foucault, Michel (2008). Vigilar y castigar. El nacimiento de la prisión. Buenos Aires: Siglo XXI.

González, César (2020). La venganza del cordero atado. Buenos Aires: Ediciones Continente.

Hegel, G.W.F (1970). Filosofia de la historia. Barcelona: Ediciones Zeus.

Honneth, Axel (1997). La lucha por el reconocimiento. Por una gramática moral de los conflictos sociales. Barcelona: Crítica.

Honneth, Axel (2007). Reificación: un estudio en la teoría del reconocimiento. Buenos Aires: Katz.

Honneth, Axel (2009a). Crítica del Poder. Fases en la reflexión de una Teoría Crítica de la Sociedad. Madrid: Antonio Machado Ediciones.

Honneth, Axel (2009b). Patologías de la razón. Historia y actualidad de la Teoría Crítica. Buenos Aires: Katz.

Honneth, Axel (2011). La sociedad del desprecio. Madrid: Trotta.

Kant, Imannuel (2003). Crítica del discernimiento. Madrid: Antonio Machado Ediciones.

Kristeva, Julia (1989). Poderes de la perversión. Ensayo sobre Céline. Buenos Aires: Siglo XXI.

Luna, Félix (1971). El 45: crónica de un año decisivo. Buenos Aires: Editorial Sudamericana.

Martínez Estrada, Ezequiel (2005). ¿Qué es esto? Buenos Aires: Colihue.

Nancy, Jean-Luc (2003). Corpus. Madrid: Arena Libros.

Revista de Humanidades de Valparaíso, 2020, No 16, 215-237

(c) $(1) \Theta(-)$ CC BY-NC-ND 
Axel Honneth: el conflicto social y los modos de la mirada. Apuntes para pensar el problema más allá del reconocimiento

Jorge Ariel Palacio

Olalla, Marcos (2007). Civilización y barbarie. Dos interpretaciones del rol letrado frente al proyecto modernizador en América Latina: Sarmiento y Martí. Cuyo. Anuario de filosofía argentina y americana, 24, 187-204.

Platón (2017). Alcibíades. Madrid: Miluno Editorial.

Rivera Cusicanqui, Silvia (2016). Complejo de t'ara, complejo de q'ara: ¿Es posible salir de las cárceles de la identidad? En: Oberti, Alejandra, Rodríguez, Florencia, Bacci, Claudia (Comps.), Coordenadas contemporáneas de la sociología: tiempos, cuerpos, saberes. Conferencias de las XI Jornadas de Sociología de la Universidad de Buenos Aires, pp. 73-94. Buenos Aires: Imago Mundi.

Romero Cuevas, José Manuel (2009). J. Habermas, A. Honneth y las bases normativas de la Teoría Crítica. Constelaciones. Revista de Teoría Crítica, 1, 72-87

Romero Cuevas, José Manuel (2013). El concepto de crítica en J. Habermas y Axel Honneth. Revista de humanidades y ciencias sociales, 4, 15-48.

Sarmiento, Domingo Faustino (2007). Facundo. O civilización y barbarie en las pampas argentinas. Buenos Aires: Gradifco.

Sartre, Jean-Paul (1996). El ser y la nada: ensayo de ontología fenomenológica. Barcelona: Ediciones Atalaya.

Sivak, Martín. (2005). El Doctor: biografía no autorizada de Mariano Grondona. Buenos Aires: Aguilar. 
